\title{
Escape Room as Game-Based Learning Process: Causation - Effectuation Perspective
}

\author{
Jonna Järveläinen \\ Turku School of Economics, University of Turku \\ jonna.jarvelainen@utu.fi
}

\author{
Eriikka Paavilainen-Mäntymäki \\ Turku School of Economics, University of Turku \\ eriikka.paavilainen-mantymaki@utu.fi
}

\begin{abstract}
Commercial escape rooms have provided inspiration for an increasing number of educational escape rooms, where students use their learning to solve problems and "escape" a room in a certain time. However, only few escape room studies have been published in the game-based learning research area, although it has been interested also in learning processes. In this study, we apply causation effectuation theory to observe the learning processes of three student teams solving tasks in an escape room context. The escape room was part of an information systems science research methods course, where the learning process of 18 international students were observed on video recordings. Different learning processes were observed in the teams and causationeffectuation theory explained for example the experimental or instruction following team behavior.
\end{abstract}

\section{Introduction}

Teachers have increasingly applied game-based learning in the form of educational escape rooms to increase student motivation and engagement, introduce experiential learning and dividing large tasks to more simple phases in a game. Commercial escape rooms were first introduced in Japan few decades ago [12, 45] involving a series of puzzles, riddles and tasks often related to a theme or story, which have to be solved in a certain time before the participants can "escape" the room. Some educational escape room examples include pharmacology students solving puzzles to save Batman from being poisoned by the Riddler [22], and computer science students e.g. investigating the metadata of an IP address to find GPS coordinates [4].

Causation - Effectuation theory has been applied in entrepreneurship and organization research to describe how new business ideas are formed into companies $[31,38]$, as well as how entrepreneurial organizations learn, strategize and operate $[37,38]$. Effectuation and causation are seen in the theory as two ends of a continuum, effectuation representing a non-linear, adaptive, experiential and contextually and situationally flexible way of working, whereas causation is seen as a formalized, systematic, linear and invariable way of working. In learning context, experiential learning cycle and scaffolding (where one task is building upon the already accomplished tasks) seem closely related to effectuation $[25,28]$ whereas causation resembles problem-based learning [39].

Prior escape room literature in higher education has emphasized the practical contribution, for example by describing how escape rooms are developed and implemented $[9,45]$, but also theoretical contribution focusing on the outcomes such as how students learned $[6,15]$, or how their motivation developed [4]. Escape rooms usually involve several tasks [47] and can therefore be considered as processes, which has been of interest in game-based learning literature [2, 26]. Also there has been call for studies focusing on how learning happens in certain game design [7]. Therefore we now apply theory of causation and effectuation to this field to explain how teams behave and learn while solving the problems and doing the tasks in the game.

An escape room was used as an exam to increase student motivation and to show their ability to use the new skills on a Master level course in information systems science on research methods. Students competed in teams by solving tasks related to research methods, such as finding a suitable theory, methodology and data gathering methods for given research question (RQ), and selecting data sources, which they would need for solving the RQ i.e. scaffolding [34].

The aim of this paper is three-fold. First, we present a link between current literature on causation and effectuation and experiential and problem-based learning theories that are useful for understanding the learning processes in educational escape rooms. Second, we explain how causation and effectuation was practically observed and applied on a research method course. Third, we provide suggestions how causation and effectuation perspective can help to understand student behavior in escape room context. 


\section{Theoretical background}

The roots of effectuation and causation lie in entrepreneurship and organization research [5, 17, 33], where entrepreneurs and managers strategize effectually, by using the means at hand as best as they can to reach a yet unknown end result, and/or causally, by using a given set of means to reach a specific goal. E.g. entrepreneurship education and organizational learning literatures $[14,18,20]$ has broadened the scope of this research stream and discussed, how entrepreneurship students could apply effectuationcausation in courses dealing with start-ups and innovations [40].

In educational escape rooms the focus is on learning that can take place in different ways. One approach is causal, rational learning where sustained patterns, rules, repetition, mechanisms and conventions are essential [e.g. 42]. Here the learning process is designed for a certain set goal and the same systematic and formalized learning mechanisms are repeated to ascertain the same learning results. For example teams formulate an operating culture for themselves through common co-operating experience, and in later tasks repeat the same patterns to fulfil the tasks. Another approach focuses on experimentation, evaluation and assessment [e.g. 30]. In this approach, compared to causal learning, a limited rationality is adopted and learning is more adaptive and e.g. experience and memories, information availability, incentives and beliefs influence (intervene) the learning mechanisms. As an example, here e.g. the team members' individual knowledge and capabilities are used to complement the team skill-base in completing the tasks. A third approach addresses effectuation, where unbounded rationality is assumed [38]. Here learning is iterative, experimental, evolutionary, flexible and adaptive, as the means of learning are known, but the learning goals are not predetermined or unchangeable as they may change depending on the context, situation and the learning mechanisms (process). In a team context the team works on fulfilling the task in a contextually viable manner, modifying their conduct according to the changing task needs and aiming for a beneficial, though yet unknown end result. These approaches do not, however, exclude each other and many times it is beneficial to use them in combination in attempts of getting the appropriate learning effects [e.g. 37, 38].

Rae [35] describes entrepreneurial learning to be a dynamic process where awareness, reflection, association and practical application transform experience into functional learning. This echoes the experiential learning concept discussed by Kolb [28], where learning is seen as a cyclical process involving experiencing, experimenting, observing and conceptualizing and through these steps knowledge is accommodated, diverged, assimilated and converged into new comprehension. Both of these, in turn, share the features of effectuation [38], whereas causal learning resembles more problem-based learning [39] with its set goal giving purpose, stimulus, direction and construction for the learning task.

\section{The context and design of the escape room}

The first author designed a flipped classroom based course on Research methods in Information Systems Science, with plenty of online resources available in Moodle and self-learning quizzes and assignments in which students had to apply their learning and where the teacher would be a supervisor of assignments. The online resources in Moodle included 27 short videos on research methods, 22 research articles on different methods, 12 links to other resources such as books, academic phrase banks, literature databases etc. The students had eight assignments on the course (e.g. develop RQs for qualitative and quantitative study, analyze data), which were peer and teacher reviewed in Moodle and 3 multiple choice quizzes for evaluating their own learning. Before the final assignment, an 812 page research proposal for their Master's thesis, the teacher wanted to evaluate somehow their learning. Instead of a conventional exam, a novel approach of a physical escape room was chosen.

Educational physical games, such as some escape rooms, are also part of game-based learning literature stream. In addition to exergames, physical games such as board games, customized card games and roleplaying - have been used e.g. for language, microbiology, and software engineering teaching [1, 11, 43]. These games have been found effective in awareness raising e.g. in disaster awareness [10] and computer security [13], the teachers found the latter also recommendable, but the impact of physical games seems to have mixed results [3].

Educational escape rooms have become one of the latest trends to improve student motivation [4]. Pharmacy students try to solve medication related puzzles to get an access for a placebo injection to treat a diabetes patient [15]. Game architecture students build team cohesiveness in a mixed reality escape room game [45]. Educational escape rooms have been used by libraries for information search [6], team building [46, 47] and also for school children [32].

Escape rooms are playful, cooperation-based games $[32,45]$ often designed for teams. They require social problem solving, where, for example verbal expression of player's ideas i.e. "thinking aloud" has been found to be very useful [26]. The goal of the escape room is 
to find e.g. a key or a code to flee from the game situation by solving different kinds of puzzles together with the team in a certain time. The time limit creates conflict and challenge to the clear goal of escaping; if the players are not fast they might not reach the goal $[23,24]$. In educational escape rooms, the puzzles are designed to be challenging, which seems to predict very well the perceived learning [19]. However, in order to avoid yielding before too difficult tasks, there usually are available hints or clues for advancing [44].

The teacher applied the EscapeED framework for the escape room development [8, 9]. First, participants were identified as the Master level students on the research methods course for international students (24 students in total), and the complexity of tasks should not obstruct the students' focus on the subject matter. The students would do the test in 4-6 person teams, so it would not take too much time to monitor, the size of the team conformed with a typical student team size and a team would have 45 minutes for the exam. In order to avoid teams revealing hints to others, the teams would compete against each other with time and logical arguments used in solving the tasks.

A group of 3-4 teachers with experience on teaching research methods and escape rooms decided the objectives for learning together. The initial idea was that the students would need to operationalize a study based on a given RQ and a set of alternatives for each task (to lower the task complexity [44]). First, they would select suitable literature for the RQ, then a methodology, then data collection methods and then data sources. More thorough process was discarded as too time consuming. Since the other teachers were from different disciplines, the first author developed an IS related RQ "How do organizations prepare for operational interruptions in CRM migrations?"

The teacher group agreed that to create a real escape room atmosphere, the room needed a narrative: one team member had accidentally met a CEO from a company struggling with a CRM migration in the near future and wanted to employ the team member for a Master's thesis project to study how operational interruptions could be avoided. There were no rooms at the university, which could be locked from outside, and therefore the "escape" would have to be arranged differently. In the narrative, the team had been helping the member to prepare a presentation on the study for the company board members on a previous night, but students had ended up partying and the team had woken up with disappeared notes and the team member (about to present the proposal) had been handcuffed to a chair without the key.

Next phase of the EscapeED framework [9] is the puzzles. For the first task, the first author developed a set of 12 different numbered theories or literature areas (from technology acceptance model (TAM) to mindfulness) described very shortly on pieces of paper. The numbers of these theories would be used as the key for the first combination lock. The room chosen for the game included a cupboard and a drawer, which could be locked with combination locks. From the cupboard with this combination lock, the students would find the team member's handwritten notes on the company and short case descriptions of companies, who have experienced operational interruptions when implementing a new information system. Based on these notes, students should choose a suitable methodology for the RQ, and find a code for the suitcase combination lock from a case methodology book containing a post-it note on a page, the page number of which was the key to the next lock.

From the suitcase, students would get a large sheet of paper listing seven numbered data gathering methods and seven numbered samples of data in random order. From this sheet, students would combine the methods to data samples, select the appropriate data gathering methods and add the combination of numbers to get a key to the third combination lock on the drawer. Then students would get a list of different data sources (documents, meetings and potential interviewees) with some underlined letters on each row. They would choose six different data sources from the list, and the underlined letters of correct choices could be used for an anagram indicating the hiding place of the handcuff key.

Equipment for the game consisted of the combination locks and sheets of paper where the tasks were. Initial idea was to have some of the tasks also online, but for this first escape room experiment we did not have the resources or time to develop online tasks and decided that only a timer clock on a large screen was sufficient. One experienced escape room enthusiast recommended that we should choose a meeting room instead of a classroom to create a more real atmosphere, and also possibly dim the lights in the room and bring in some props. As the narrative hinted that the student team had been involved in a not very memorable night of planning the presentation, we brought empty bottles of wine and potato chip bags to the room in addition to the game-relevant props.

Before the actual implementation of the escape room, we decided to test it. Three colleagues (two doctoral students and one more experienced researcher) were recruited for the test a week before the actual implementation. First author was handcuffed to the chair, and wrote field notes while observing the test participants, who managed to find the key in 42 minutes. Based on the observations, and the methodological experience of the test participants, the initial design was decided to be too difficult. The tasks 
were facilitated by creating an operationalization table to a board, from which the students would see the sequence of tasks including the required number of choices they had to find in each task. Also a hint for expected calculation formula was included in the data gathering method sheet. It was also decided that the teams would receive the narrative via e-mail one hour before their session started, so no time would be spent on reading the narrative while in the escape room.

\section{Research design}

As we wanted to study causation and effectuation in a game-based learning context (here escape room), we chose to apply the comparative case study [36] approach, each observed team acting as a case.

The gathered data for the purposes of this research consisted of video recordings of the teams doing the escape room exercise. The teams were informed that the game sessions would be recorded for research purposes, if it suited the participants. Therefore, we gathered data from 3 teams agreeing for the recording (out of 4). The video data production and analysis followed the guidelines by Knoblauch and Tuma [27]. The escape room game provided a natural frame and context for the videos; they were experiment-type controlled ethnographies [27], where the behavior of a student team was observed and moderated in a designated classroom environment during the allocated time for the game. The teams exited the escape rooms in following times respectively: 36' 36', 36' 23 ', and 43' 06 ', equaling the length of the videos that form the data corpus. The relevant video content for analysis was formed of discourse, gestures, expressions, rhetoric, interaction, movement in the class room i.e. all the audio-visually available recorded material, accompanied by the moderating/instructing teacher's field notes and feedback received from the team members after the exercise.

A comparative case analysis between the teams was conducted [36]. The comparability of the video data was very good, as all the teams did the same exercise in the same place with the help of the same teacher. The video analysis proceeded iteratively, where the coding began with preliminary, theory-driven codes and was complemented with data-driven codes that emerged from the videos during the analysis. The videos were coded by both the researchers. During this process the researchers discussed the meanings and interpretations they had given to their observations, such as the actions, dialogue and body language, and when competing interpretations emerged, these were addressed to find conformity. The researchers viewed the videos several times until no new codes emerged. Altogether 9 pages of detailed analysis notes were made during the video-viewing. After numerous iterations the researchers ended up with six codes (presented in table 1). The focus in the analysis was on the critical event sequences [21] that were identified through the codes. These sequences dealt with problem solving, decision-making patterns and team dynamics when working on the escape room exercise. A typical event sequence chronology began with the team receiving instructions for the task; this was followed by teamwork in finding a solution to the task; and the sequence ended by the teams solving the task and gaining access to another set of task instructions.

\section{Results and discussion}

The teams had received the game narrative by email just before the starting time. The game started for each team by selecting a "team leader", who was handcuffed to the chair as the game narrative implied. The "team leader" was therefore bound to a certain place around the table and was not able to move and search for locks (located on another area in the room), but could participate in the intellectual puzzle solving since teams brought the discovered tasks to the table.

All recorded teams had 6 members of which four took a quite active, discussing role and two members contributed only a few times to the solution somehow. The silent members were also quiet during the other group sessions, which may be related to language barriers or introvert temperament. However, this behavior was not apparent in the not recorded team, which had four members only, and all contributed actively although three members out of four had not been very active participants during the other learning sessions of the course. This may indicate that four members per team could be optimal for this kind of escape room game.

Team 1 had a very structured approach to the game. Despite their selected "team leader", one member took a position as the narrator and as actual team leader:

Actual team leader (ATL): The topic is [reading and pointing the case description] service interruptions in large companies during switching from one system to another, so like change management within IT, I guess... And then we can find now theories and literature areas, first three papers. Well, we can maybe start [points puzzle pieces and makes sorting gestures] like this and see if they fit.

Chosen team leader (CTL): Yeah.

ATL: 'Cause I think this is a model, so that is a method...right?

CTL: Mm, it's TAM.

ATL: Well, is it a theory, it's a theory then?

Teacher: They are all theories or literature areas. 
ATL: So we have to choose three, the three best ones for...

Teacher: For that research question, yes."

So the ATL ensured the correct understanding of the task and then continued thinking aloud [26] the process, which she did in the beginning of every task and also sometimes during the solving process. The three active members participated in the process by discussing, suggesting solutions aloud, by pointing or by trying physically to find and open the locks. Firstly, they piled suitable theory puzzle pieces to find a solution for the first task by discussing, comparing and noticing similarities between theory puzzle pieces and the RQ. After solving the code and finding the second task, again ATL ensured what the task aim was. After silent reading, they immediately understood the correct methodology, but finding the solution for the second lock required hints from the teacher to use the books. The third task (choosing suitable data collection methods) was the most challenging one for the team. After ATL ensured the aim, they read silently and started to think aloud of possible solutions.

The ATL vocalized the assumed strategy and other members started to suggest alternatives or silently read the paper and point to solutions, two of which were easily discovered (first three code numbers found). However, the third suitable method was difficult to find, and the team suggested solutions and found a correct method, but not the correct sample, so finally the ATL started to try opportunistically different numbers to the remaining lock and opened it. In the last task, the team applied the same logic of checking the aim, silently reading, pointing and suggesting solutions aloud. They also asked for some validation from the teacher and solved rather quickly the final puzzle with a couple of hints.

Team 2 did not have a clear leader, but the four active members had an equal, discussing teamwork logic. This was the only team that was interested on time: they asked how long team 1 played the game. They brainstormed different ideas, and often started by excluding obviously wrong solutions. In the first task, after silent reading, checking the aim and excluding some wrong puzzle pieces, they divided the remaining theory pieces into two groups and picked the most suitable ones in two separate sub-teams. One of the sub-teams discussed, but the other sub-team comprised of the chosen team leader and the two quiet members, who just nodded on CTL's thinking aloud process. Then they discussed the results of the sub-teams, noted the similarity between theory pieces and RQ, and excluded again more pieces. After trying to fit in the familiar TAM, teacher hinted that it is not correct. They found the last piece based on similarity of text in the piece and RQ, and opened the lock.
The second task of choosing the appropriate methodology was understood very quickly, but the team still brainstormed until they received a hint where the code for the next lock might be. The third task took more time. After checking the aim and discussing tactics, the participants suggested solutions, excluded an obviously unsuitable one, and noticed that they could first choose suitable methods and afterwards connect those to samples of data, instead of connecting all methods and samples and then pick the suitable ones. They validated their first solutions with the teacher, and after discussing new suggestions, one member opened the lock by trying the remaining combinations, before the others could find the solution. This member then aimed for a final "sprint" in the fourth task and suggested that he reads the list aloud and others just indicate whether that item on the list might be possible.

M(ember)3: So what do we need for data?

M2: Where's the clock?

Teacher: There's the clock. You need six types of data now.

M3: Ok. So what do we need from the interviews?

M2: [takes a pen and starts to read from the list of alternatives] So, just say no: "Annual report"

CTL: For this? No.

M2: "Board meeting minutes"?

M3: Minutes?

M2: Like the notes, minutes are notes.

M3: Oh! ... well, no.

M2: No. CRM migration meeting minutes. Yes.

This tactic was experimental and efficient, and they solved with couple of hints the place where handcuff key was hidden.

Team 4 was all male team, who were very talkative and occasionally goal-oriented. Their teamwork included discussion, reading papers aloud and they laughed more than the other teams. The first task started with opportunistic behavior.

First, they tried to check whether other teams had filled the operationalization table on the flip board and left their solutions to the room. Then after silent reading, they switched to reading and thinking aloud and discussion in order to find consensus. This team also recognized TAM, which they tried to include to the theory base although it was not connected to the problem area. After solving the first task, the methodology task seemed to be very difficult:

M1: We have action research, case study research..

M4: We have a..

M1: Oh, there are notes in it [browses through the case study book].

M3: No, no, it's just the parts you should read. So like, there is a place for conclusions, so you don't have to read entire chapter. 
M1: You think so?

M4: So then what do we need for data?

Teacher: No, first methodology.

[M1 and M2 reading book covers].

[Silent pondering]

M1: Ok, let's concentrate.

[M4 starts again reading the task paper aloud.]

M1: We need to get the data to know how to avoid service interruptions during the switch. How can we get those data?

[question for teacher about text and answer]

[team members show books to each other]

M1: Literature research, I think not, because we have to get the data, so let's put it away. So what we have left?

M2: Feminist methodology, let's put that away also.

M1: Yeah. Maybe they are just here to create noise. I think focus group would also be interesting.

M4: And also "Foundations for mixed methods".

M1: Mixed methods, is there also an answer to like using multiple...

Teacher: H'm, one methodology is enough now M1: Oh. Okay.

Although this team had also previous research method courses and experience, and were sure of their knowledge, they had difficulties to understand the difference between methodologies and methods. They discussed the second task extensively and had difficulties to concentrate, possibly because the task was too difficult for them. One member also ignored the clue of blue post-it notes on the case methodology book, which led the team to a wrong direction. With discussion and couple of hints, they finally solved the second task. However, they did know their methods and solved the third task relatively quickly starting with thinking aloud the aim of the task and discussing tactics, followed by brainstorming leading to two correct answers and a hint from teacher that those were correct ones. Then they continued brainstorming and used Wikipedia to check meaning of the selected method. After more brainstorming, they finally found the correct combination. On fourth task, they noticed that time was running out and they decided to trust on their intuition, but required some hints also before finding the final solution. In the end, they tried to open the handcuffs without the key since solving the puzzle seemed to take too long. They also sought validation from the teacher, and tried to experiment by asking if their guess had been correct.

Table 1 provides a summary of the analysis by themes and codes, accompanied by linkages to the effectuation and causation perspectives. The codes were: (1) Non-verbal cues; (2) Verbal interaction; (3) Strategizing tactics; (4) Teacher mediation; (5) Misunderstandings; and (6) Opportunistic behavior.

Table 1. Task Solution Tactics and Times of Teams.

\begin{tabular}{|c|c|c|c|}
\hline & Team 1 & Team 2 & Team 4 \\
\hline $\begin{array}{l}\text { 1st task } \\
\text { (theories) }\end{array}$ & $\begin{array}{l}\text { moving theory puzzle pieces (1), } \\
\text { checking RQ and the aim of the } \\
\text { task ( } 3 \text { ), discussing (2), silent } \\
\text { reading + pointing (1), suggesting } \\
\text { solutions ( } 2 \text { ), noticing relevant } \\
\text { words (2), checking the task (3), } \\
\text { discussion about comparing and } \\
\text { choosing the correct ones ( } 2 \text { ) } \\
\text { Tactical certainty before } \\
\text { discussion and thinking aloud } \\
\text { with silent working indicating } \\
\text { that the team was employing } \\
\text { causation in solving task } 1 \text { i.e. } \\
\text { following the instructions and } \\
\text { working more individually than } \\
\text { as a unified team. (time: } 5 \text { '30’') }\end{array}$ & 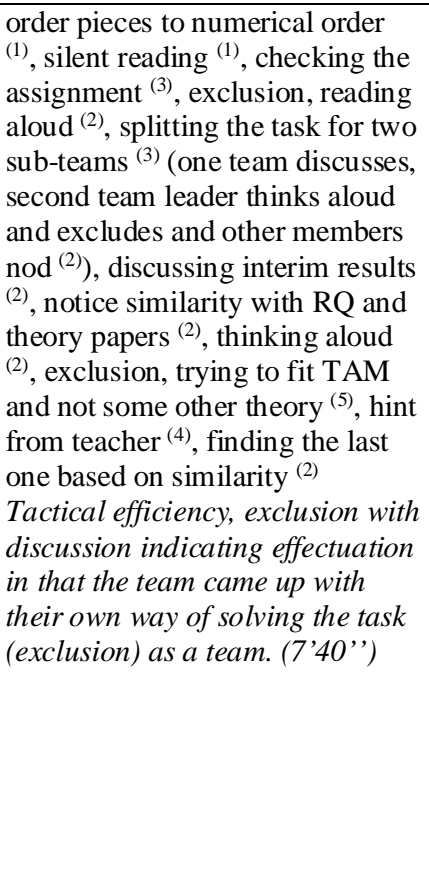 & 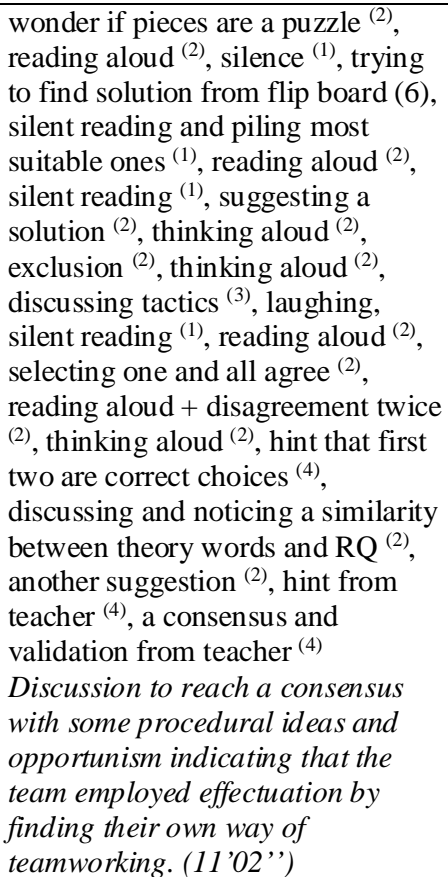 \\
\hline $\begin{array}{l}\text { 2nd task } \\
\text { (methodology) }\end{array}$ & $\begin{array}{l}\text { checking the aim of task }{ }^{(3)} \text {, team } \\
\text { leader thinks aloud about the } \\
\text { selection process }{ }^{(3)} \text {, silent }\end{array}$ & $\begin{array}{l}\text { suggest reading aloud, but } \\
\text { disagreement }{ }^{(3)} \text {, then silent } \\
\text { reading }{ }^{(1)} \text {, summarizing the }\end{array}$ & $\begin{array}{l}\text { reading aloud }^{(2)} \text {, discussion } \\
\text { about props, }^{(2)} \\
\text { silence }^{(1)}, \text { hint for books }^{(4)} \text {, }\end{array}$ \\
\hline
\end{tabular}




\begin{tabular}{|c|c|c|c|}
\hline & $\begin{array}{l}\text { reading }{ }^{(1)} \text {, hint to look books }{ }^{(4)} \text {, } \\
\text { all start to browse books }{ }^{(1)} \text {, find } \\
\text { case study book with blue post-it } \\
\text { notes }{ }^{(1)} \text {, think they have to } \\
\text { choose } 3 \text { books }{ }^{(5)} \text {, teacher hints } \\
\text { that not }{ }^{(4)} \text {, suggest trying page } \\
\text { number }^{(2)} \\
\text { Tactical certainty, team leader as } \\
\text { a narrator before silent working } \\
\text { with some discussion indicating } \\
\text { that the team continues in task } 2 \\
\text { with causation approach that is } \\
\text { supported by hints from the } \\
\text { teacher. (5'24') }\end{array}$ & $\begin{array}{l}\text { contents }^{(2)} \text {, check the books }{ }^{(1)} \text {, } \\
\text { still thinking aloud }{ }^{(2)} \text {, starting } \\
\text { from qualitative methods and } \\
\text { suggesting case study }{ }^{(2)} \text {, noticing } \\
\text { blue post-it notes }{ }^{(2)} \text {, trying page } \\
\text { number as a code to unlock }{ }^{(2)} \\
\text { Discussion based problem solving } \\
\text { allowing disagreement indicating } \\
\text { effectuation in that the team } \\
\text { shares their 'incomplete' } \\
\text { thoughts and suggestions to find a } \\
\text { solution in consensus. (6'20') }\end{array}$ & 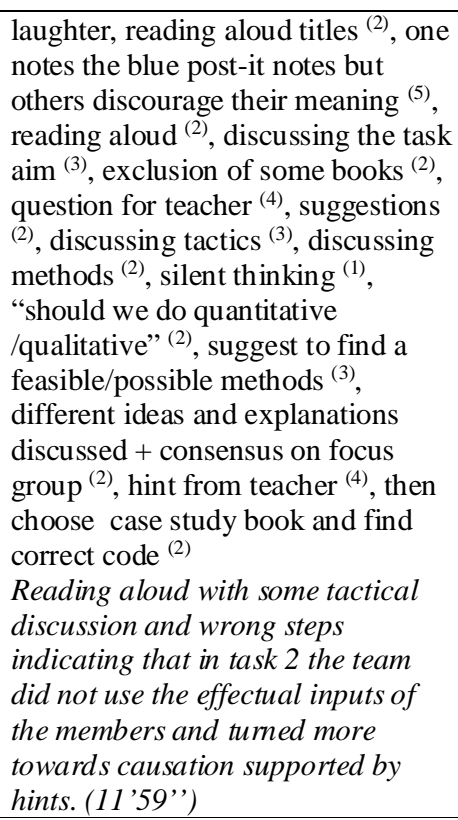 \\
\hline $\begin{array}{l}\text { 3rd task (data } \\
\text { collection } \\
\text { methods) }\end{array}$ & 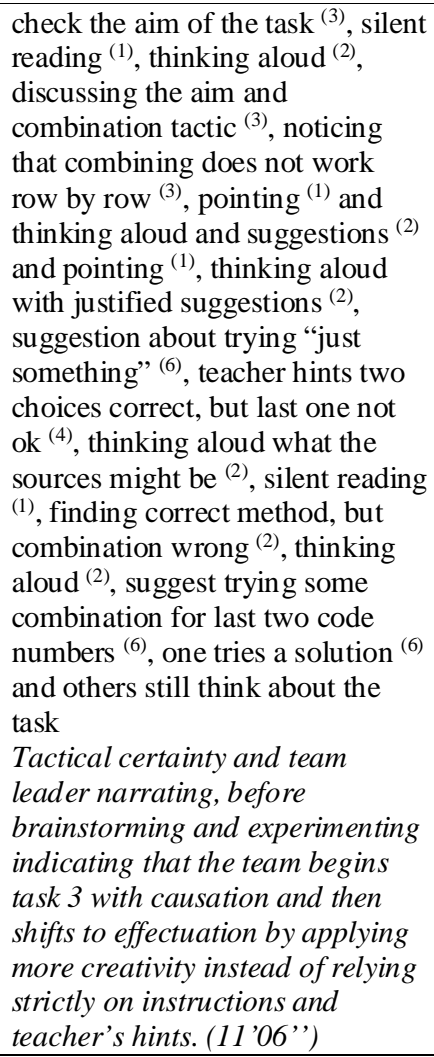 & 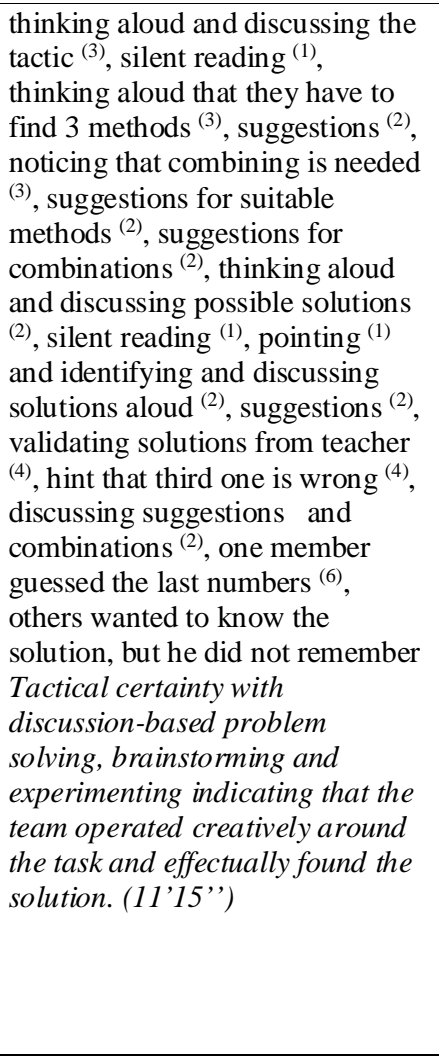 & 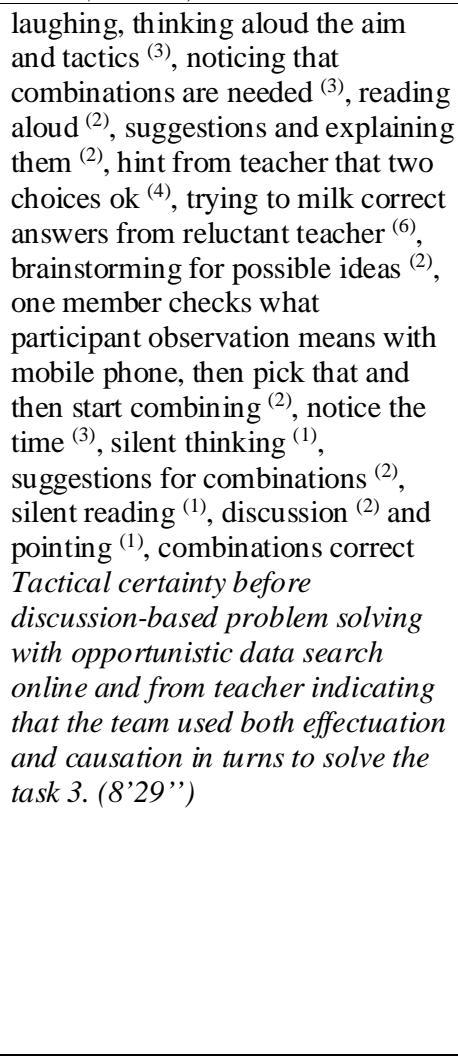 \\
\hline $\begin{array}{l}\text { 4th task (data } \\
\text { sources) }\end{array}$ & 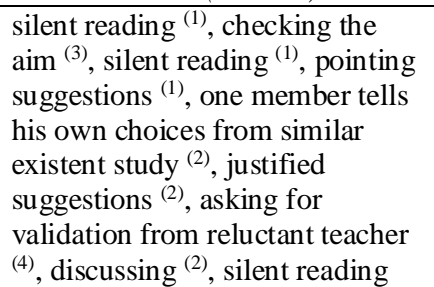 & $\begin{array}{l}\text { checking the clock }{ }^{(3)} \text {, reading } \\
\text { aloud possible sources, others } \\
\text { suggest in-/exclusion }^{(2)} \text {, } \\
\text { discussion }{ }^{(2)} \text {, hint from teacher } \\
\text { on number of sources needed }^{(4)} \text {, } \\
\text { writing the selected letters }^{(1)} \text {, } \\
\text { asking validation from teacher }{ }^{(4)} \text {, } \\
\text { noticing problems with the }\end{array}$ & $\begin{array}{l}\text { silent reading }{ }^{(1)} \text {, inclusion } \\
\text { suggestions by one }{ }^{(2)} \text {, one thinks } \\
\text { that first letters will be used, but } \\
\text { other show that not }{ }^{(5)} \text {, discussion } \\
\text { tactics }{ }^{(3)} \text {, one thinks aloud and } \\
\text { suggestions }{ }^{(2)} \text {, one suggests } \\
\text { choosing procedure }{ }^{(3)} \text {, one starts to } \\
\text { crack the handcuffs }^{(6)}, \text { asking for }\end{array}$ \\
\hline
\end{tabular}




\begin{tabular}{|c|c|c|c|}
\hline & $\begin{array}{l}\text { pointing }{ }^{(1)} \text {, hint from teacher } \\
\text { about needed number of sources } \\
{ }^{(4)} \text {, checking letters, discussion } \\
\text { about solutions }{ }^{(2)} \text {, double- } \\
\text { checking of letters }{ }^{(2)} \text {, checking } \\
\text { the aim }{ }^{(3)} \text {, notice that two letters } \\
\text { are missing }{ }^{(3)}, \text { finding the "door" } \\
\text { and thinking about remaining } \\
\text { letters }{ }^{(2)} \text {, finding the last word }{ }^{(2)} \\
\text { Silent working and tactical } \\
\text { certainty, discussion-based } \\
\text { problem solving with hints and } \\
\text { validation from teacher } \\
\text { indicating that the team returns to } \\
\text { causation in task } 4 \text {, which seems } \\
\text { to be the dominating trait of team } \\
\text { 1. (14'38') }\end{array}$ & $\begin{array}{l}\text { solution }{ }^{(3)} \text {, silent reading }{ }^{(1)} \text {, } \\
\text { reading aloud and discussing and } \\
\text { checking the chosen letters }{ }^{(2)} \text {, } \\
\text { two members start finding key }{ }^{(6)} \text {, } \\
\text { others try to solve the anagram, } \\
\text { one suggests a "door" (2) and then } \\
\text { soon they understand the other } \\
\text { word } \\
\text { Efficiency-oriented exclusion } \\
\text { procedure based on minimal } \\
\text { discussion and opportunism } \\
\text { indicating that the team employs } \\
\text { effectuation by using their own } \\
\text { way of working and attempting to } \\
\text { shortcut to the solution. (10'53',) }\end{array}$ & 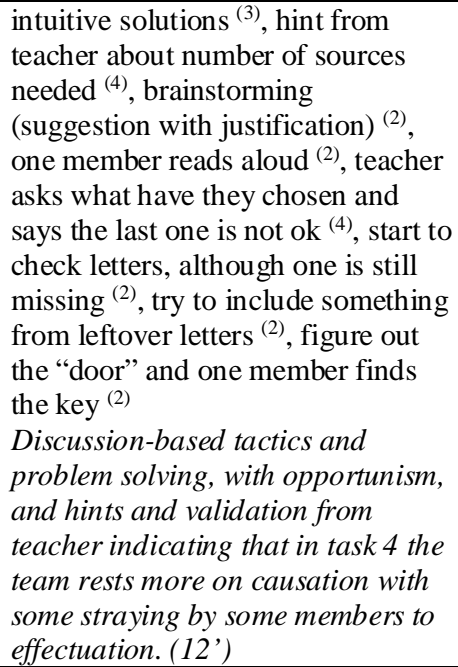 \\
\hline
\end{tabular}

In the context of game-based learning and escape rooms, the characteristics of both effectuation and causation could be considered relevant $[37,38]$, as the end result of the game is unknown in advance (escape vs. no escape), there are specified tasks to be solved during the game (the means become known while playing), the game has a clear goal (escape in time) and the team inside the room can solve the tasks the way they see the best (no predetermined mechanisms for solving the tasks, though there are rules in the game).

In effectuation the actors begin what they have, who they are, what they know and how they use contingencies [38]. The teams came with their knowledge although it was possible to look for answers with their mobiles, but since the tasks were emphasizing application, and time was limited, only one person checked definition of one method online.

The teams' ways of working was observed to be dependent on the team leaders' learning and operating style, the members' learned typical teamwork cultures and the tolerance of uncertainty. If the team leader had a strong role in the team and guided the teamwork, his/her learning and operating style easily translated to the team's operating style, i.e. an effectual leader took the team to the effectual path and a causal leader to the causal path [16, 37, 38]. In teams where the learned teamwork culture was less interactive and focused on individual, separated efforts, a causal style, by definition, was more suitable. On the contrary, in teams that emphasized brainstorming and joint efforts an effectual style was observed [16, 37, 38]. These observations were supported by the feedback the students gave after the escape room exercise.

Based on the data it seems that Team 1 was employing causation, Team 2 effectuation and Team 3 a mix of both. In terms of uncertainty tolerance, teams with causal style rested on the instructions and teacher hints and validation of solutions, i.e. certainty that they have cracked the task, before action. Effectual teams in turn experimented, sought cues from the classroom, opportunistically tried to shortcut tasks, brainstormed with disagreements and did not require certainty that their actions would necessarily lead to cracking the task. These teams also used a "plan to fail" game logic, they experimented and tried to fail fast in order to get to the correct solution [41].

The teams were surprisingly persistent, they wanted to solve the problems even if they could have guessed some solutions [44], and finally some of them did. Team members had different tempo in problem solving, due to perhaps differences in temperament or learning style, which led to persons taking leadership or active position in problem solving when some of the participants observed more and were quieter. The team dynamic was very different with limited time than they were used to in weekly or longer assignments.

\section{Implications}

This study addresses the call for understanding how learning happens in games [7] by examining qualitative video data from a physical escape room, In other words we observed the process rather than learning outcomes or their effectiveness, which has been focus of many studies in this area [29]. The escape room setting provided an excellent ground for observing learning styles that would have otherwise been undetected; the whole task sequences with audiovisual data of three teams in a comparable context.

From the theoretical perspective, the study contributes in connecting effectuation theory with experiential learning, as well as problem-based 
learning with causation, which were exemplified by the teams' behavior within the game. These observations depict the content of the learning events, shed more light on the team dynamics in the learning situation and illustrate the learning process. Identifying these similarities, acknowledging their interlinkages and bringing these theories together can enhance the explanatory power of game-based learning studies. The theory of effectuation seemed to provide some content explanations about the ways students operate and learn in a gamified exercise situation. In connection with this, both the process nature of emergent experiential and constructed problem-based learning were detectable in the teams' behavior. Effectuation and causation revealed team dynamics, the leader's role in steering the task, the existing learning cultures related to teamwork and the students' tolerance of uncertainty. The teams also demonstrated well the different ways of learning; causal, effectual and a mix, which is in line with the literature $[28,37,38,39]$. Based on the student feedback, learning took place in all the teams, though their paths (effectual, causal, mix) varied. This finding provides interesting insights, in line with the effectuation theory $[37,38]$, how similar results can be reached with very divergent approaches.

Our practical contribution lies in the escape room design and the lessons we learned from this implementation. Designing the escape room was timeconsuming, but an excellent way to evaluate teaching and learning. In this case, the teacher observed confusion with the methodology and method concepts, and the students understanding of data certain method produces. In the future, we aim to strengthen the visibility of the narrative, expect a consensus from students for receiving a hint and clarify task sequence.

The limitations of the study include the small number of students on the course, and thereof the small amount of observational data. The student groups were very heterogenic and cultural differences might explain some differences in the gaming process, but this was out of the scope of this study. Perceived learning or motivation was not addressed, but focus on observing the process provides an interesting area for further research.

\section{References}

[1] Baker, A., E.O. Navarro, and A. van der Hoek, "An experimental card game for teaching software engineering processes", Journal of Systems and Software 75(1-2), 2005, pp. 3-16.

[2] Barata, G., S. Gama, J. Jorge, and D. Gonçalves, "Studying student differentiation in gamified education: A long-term study", Computers in Human Behavior 71, 2017, pp. 550-585.
[3] Bodnar, C.A., and R.M. Clark, "Exploring the Impact Game-based Learning Has on Classroom Environment and Student Engagement Within an Engineering Product Design Class", Proceedings of the Second International Conference on Technological Ecosystems for Enhancing Multiculturality, ACM (2014), 191-196.

[4] Borrego, C., C. Fernández, I. Blanes, and S. Robles, "Room escape at class: Escape games activities to facilitate the motivation and learning in computer science", Journal of Technology and Science Education 7(2), 2017, pp. 162-171. [5] Chandler, G.N., D.R. DeTienne, A. McKelvie, and T.V. Mumford, "Causation and effectuation processes: A validation study", Journal of Business Venturing 26(3), 2011, pp. 375-390.

[6] Choi, D., J. An, C. Shah, and V. Singh, "Examining information search behaviors in small physical space: An escape room study", Proceedings of the Association for Information Science and Technology 54(1), 2017, pp. 640641.

[7] Clark, D.B., E.E. Tanner-Smith, and S.S. Killingsworth, "Digital Games, Design, and Learning: A Systematic Review and Meta-Analysis", Review of Educational Research 86(1), 2016, pp. 79-122.

[8] Clarke, N., S. Furnell, R.V. Solms, and U. of P.C. for S. Research Communications and Network, Proceedings of the South African Information Security Multi-Conference: Port Elizabeth, South Africa, 17-18 May 2010, Lulu.com, 2011.

[9] Clarke, S., S. Arnab, H. Keegan, L. Morini, and O. Wood, "EscapED: Adapting Live-Action, Interactive Games to Support Higher Education Teaching and Learning Practices", Games and Learning Alliance, Springer, Cham (2016), 144153.

[10] Clerveaux, V., and B. Spence, "The Communication of Disaster Information and Knowledge to Children Using Game Technique: The Disaster Awareness Game (DAG)", International Journal of Environmental Research 3(2), 2009, pp. 209-222.

[11] Coil, D.A., C.L. Ettinger, and J.A. Eisen, "Gut Check: The evolution of an educational board game", PLOS Biology 15(4), 2017, pp. e2001984.

[12] Corkill, E., "Real Escape Game brings its creator's wonderment to life", The Japan Times Online, 2009. https://www.japantimes.co.jp/life/2009/12/20/to-besorted/real-escape-game-brings-its-creators-wonderment-tolife/

[13] Denning, T., A. Lerner, A. Shostack, and T. Kohno, "Control-Alt-Hack: The Design and Evaluation of a Card Game for Computer Security Awareness and Education", Proceedings of the 2013 ACM SIGSAC Conference on Computer \& Communications Security, ACM (2013), 915928.

[14] Dew, N., S. Read, S.D. Sarasvathy, and R. Wiltbank, "Outlines of a behavioral theory of the entrepreneurial firm", Journal of Economic Behavior \& Organization 66(1), 2008, pp. 37-59.

[15] Eukel, H.N., J.E. Frenzel, and D. Cernusca,

"Educational Gaming for Pharmacy Students - Design and Evaluation of a Diabetes-themed Escape Room", American Journal of Pharmaceutical Education; Alexandria 81(7), 2017, pp. 1-5. 
[16] Fisher, G., "Effectuation, Causation, and Bricolage: A Behavioral Comparison of Emerging Theories in Entrepreneurship Research", Entrepreneurship Theory and Practice 36(5), 2012, pp. 1019-1051.

[17] Futterer, F., J. Schmidt, and S. Heidenreich, "Effectuation or causation as the key to corporate venture success? Investigating effects of entrepreneurial behaviors on business model innovation and venture performance", Long Range Planning 51(1), 2018, pp. 64-81.

[18] Gibb, A., "Concepts into practice: meeting the challenge of development of entrepreneurship educators around an innovative paradigm: The case of the International Entrepreneurship Educators' Programme (IEEP)", International Journal of Entrepreneurial Behavior \& Research 17(2), 2011, pp. 146-165.

[19] Hamari, J., D.J. Shernoff, E. Rowe, B. Coller, J. AsbellClarke, and T. Edwards, "Challenging games help students learn: An empirical study on engagement, flow and immersion in game-based learning", Computers in Human Behavior 54, 2016, pp. 170-179.

[20] Harms, R., and H. Schiele, "Antecedents and consequences of effectuation and causation in the international new venture creation process", Journal of International Entrepreneurship 10(2), 2012, pp. 95-116. [21] Heath, C., J. Hindmarsh, and P. Luff, Video in Qualitative Research: Analysing Social Interaction in Everyday Life, SAGE Publications, Inc., London, United Kingdom, 2010.

[22] Hermanns, M., B. Deal, A.M. Campbell, et al., "Using an 'Escape Room' toolbox approach to enhance pharmacology education", Journal of Nursing Education and Practice 8(4), 2017, pp. 89.

[23] Huotari, K., and J. Hamari, "A definition for gamification: anchoring gamification in the service marketing literature", Electronic Markets 27(1), 2017, pp. 21-31.

[24] Juul, J., "The Game, the Player, the World: Looking for a Heart of Gameness", PLURAIS - Revista Multidisciplinar 1(2), 2010.

[25] Kapp, K.M., The Gamification of Learning and Instruction : Game-based Methods and Strategies for Training and Education, Pfeiffer, San Francisco, 2012. [26] Kim, B., H. Park, and Y. Baek, "Not just fun, but serious strategies: Using meta-cognitive strategies in game-based learning", Computers \& Education 52(4), 2009, pp. 800-810. [27] Knoblauch, H., and R. Tuma, "Videography: An interpretative approach to video-recorded micro-social interaction", The SAGE handbook of visual research methods, 2011, pp. 414-430.

[28] Kolb, D.A., Experiential Learning: Experience as the Source of Learning and Development, Prentice Hall, New Jersey, 1984.

[29] Li, M.-C., and C.-C. Tsai, "Game-Based Learning in Science Education: A Review of Relevant Research", Journal of Science Education and Technology 22(6), 2013, pp. 877-898.

[30] March, J.G., and J.P. Olsen, "The Uncertainty of the Past: Organizational Learning Under Ambiguity*”, European Journal of Political Research 3(2), 1975, pp. 147-171. [31] Matalamäki, M.J., "Effectuation, an emerging theory of entrepreneurship - towards a mature stage of the development", Journal of Small Business and Enterprise Development 24, 2017, 928-949.

[32] Nicholson, S., "Creating Engaging Escape Rooms for the Classroom", Childhood Education 94(1), 2018, pp. 4449.

[33] Perry, J.T., G.N. Chandler, and G. Markova,

"Entrepreneurial Effectuation: A Review and Suggestions for Future Research", Entrepreneurship Theory and Practice 36(4), 2012, pp. 837-861.

[34] Plass, J.L., B.D. Homer, and C.K. Kinzer, "Foundations of Game-Based Learning", Educational Psychologist 50(4), 2015, pp. 258-283.

[35] Rae, D.D., "Entrepreneurial learning: A conceptual framework for technology-based enterprise", Technology Analysis \& Strategic Management 18(1), 2006, pp. 39-56. [36] Ragin, C.C., and H.S. Becker, What Is a Case?: Exploring the Foundations of Social Inquiry, Cambridge University Press, 1992

[37] Read, S., and S.D. Sarasvathy, "Knowing What to Do and Doing What You Know: Effectuation as a Form of Entrepreneurial Expertise", The Journal of Private Equity 9(1), 2005, pp. 45-62.

[38] Sarasvathy, S.D., "Causation and Effectuation: Toward a Theoretical Shift from Economic Inevitability to Entrepreneurial Contingency", Academy of Management Review 26(2), 2001, pp. 243-263.

[39] Savery, J.R., and T.M. Duffy, "Problem Based Learning: An Instructional Model and Its Constructivist Framework", Educational Technology 35(5), 1995, pp. 3138.

[40] Shirokova, G., O. Osiyevskyy, M.H. Morris, and K. Bogatyreva, "Expertise, university infrastructure and approaches to new venture creation: assessing students who start businesses", Entrepreneurship \& Regional Development 29(9-10), 2017, pp. 912-944.

[41] Sidhu, I., K. Singer, M. Suoranta, and C. Johnsson, "Introducing Berkeley Method of Entrepreneurship-a gamebased teaching approach", The 74th annual meeting of the Academy of Management. Philadelphia, Pennsylvania, USA, (2014).

[42] Simon, H.A., "Bounded Rationality and Organizational Learning”, Organization Science 2(1), 1991, pp. 125-134. [43] Tomlinson, B., and H. Masuhara, "Playing to Learn: A Review of Physical Games in Second Language Acquisition", Simulation \& Gaming 40(5), 2009, pp. 645668.

[44] Tondello, G., H. Premsukh, and L. Nacke, "A Theory of Gamification Principles Through Goal-Setting Theory", Hawaii International Conference on System Sciences 2018 (HICSS-51), 2018.

[45] Warmelink, H., I. Mayer, J. Weber, et al., "AMELIO: Evaluating the Team-building Potential of a Mixed Reality Escape Room Game", Extended Abstracts Publication of the Annual Symposium on Computer-Human Interaction in Play, ACM (2017), 111-123.

[46] Whitton, N., "Playful learning: tools, techniques, and tactics", Research in Learning Technology 26(0), 2018. [47] Williams, P., "Using escape room-like puzzles to teach undergraduate students effective and efficient group process skills", 2018 IEEE Integrated STEM Education Conference (ISEC), (2018), 254-257. 